\title{
Shrinking Projection Method of Common Solutions for Generalized Equilibrium Quasi- $\phi$-Nonexpansive Mapping and Relatively Nonexpansive Mapping
}

\author{
Min Liu, Shih-Sen Chang, and Ping Zuo \\ Department of Mathematics, Yibin University, Yibin, Sichuan 644007, China \\ Correspondence should be addressed to Shih-Sen Chang, changss@yahoo.cn \\ Received 18 September 2009; Accepted 18 February 2010 \\ Academic Editor: Charles E. Chidume \\ Copyright (c) 2010 Min Liu et al. This is an open access article distributed under the Creative \\ Commons Attribution License, which permits unrestricted use, distribution, and reproduction in \\ any medium, provided the original work is properly cited. \\ We prove a strong convergence theorem for finding a common element of the set of solutions for \\ generalized equilibrium problems, the set of fixed points of a relatively nonexpansive mapping, \\ and the set of fixed points of a quasi- $\phi$-nonexpansive mapping in a Banach space by using \\ the shrinking Projection method. Our results improve the main results in S. Takahashi and W. \\ Takahashi (2008) and Takahashi and Zembayashi (2008). Moreover, the method of proof adopted \\ in the paper is different from that of S. Takahashi and W. Zembayashi (2008).
}

\section{Introduction}

Let $E$ be a Banach space and let $C$ be a closed convex subsets of $E$. Let $F$ be an equilibrium bifunction from $C \times C$ into $R$ and let $A: C \rightarrow E^{*}$ be a nonlinear mapping. Then, we consider the following generalized equilibrium problem: find $z \in C$ such that

$$
F(z, y)+\langle A z, y-z\rangle \geq 0, \quad \forall y \in C
$$

The set of solutions of (1.1) is denoted by EP, that is,

$$
\mathrm{EP}=\{z \in C: F(z, y)+\langle A z, y-z\rangle \geq 0, \forall y \in C\}
$$

In the case of $A \equiv 0, \mathrm{EP}$ is denoted by $\mathrm{EP}(F)$. In the case of $F \equiv 0, \mathrm{EP}$ is denoted by $\operatorname{VI}(C, A)$. 
A mapping $S: C \rightarrow E$ is said to be nonexpansive if

$$
\|S x-S y\| \leq\|x-y\|, \quad \forall x, y \in C
$$

We denote the set of fixed points of $S$ by $F(S)$.

A mapping $f: C \rightarrow C$ is said to be Quasi- $\phi$-nonexpansive if

$$
\phi(p, f x) \leq \phi(p, x), \quad \forall x \in C, \forall p \in T(f),
$$

where $\phi$ is defined by (2.3).

Recently, in Hilbert space, Tada and Takahashi [1], and S. Takahashi and W. Takahashi [2] considered iterative methods for finding an element of $\operatorname{EP}(F) \cap F(S)$. Very recently, S. Takahashi and W. Takahashi [3] introduced an iterative method for finding an element of $\mathrm{EP} \cap F(S)$, where $A: C \rightarrow H$ is an inverse-strongly monotone mapping and then proved a strong convergence theorem. On the other hand, Takahashi and Zembayashi [4] prove a strong convergence theorem for finding a common element of the set of solutions of an equilibrium problem and the set of fixed points of a relatively nonexpansive mapping in a Banach space by using the shrinking Projection method which is different from S. Takahashi and W. Takahashi's hybrid method [3].

In this paper, motivated by Takahashi and Zembayashi [4], in Banach space, we prove a strong convergence theorem for finding an element of $\operatorname{EP} \cap F(S) \cap F(f)$, where $A: C \rightarrow E^{*}$ is a continuous and monotone operator, $S$ is a relatively nonexpansive mapping, and $f$ is quasi$\phi$-nonexpansive mapping. Moreover, the method of proof adopted in the paper is different from that of [3].

\section{Preliminaries}

Throughout this paper, all the Banach spaces are real. We denote by $N$ and $R$ the sets of positive integers and real numbers, respectively. Let $E$ be a Banach space and let $E^{*}$ be the topological dual of $E$. For all $x \in E$ and $x^{*} \in E^{*}$, we denote the value of $x^{*}$ at $x$ by $\left\langle x, x^{*}\right\rangle$. Then, the duality mapping $J$ on $E$ is defined by

$$
J(x)=\left\{x^{*} \in 2^{E^{*}}:\left\langle x, x^{*}\right\rangle=\|x\|^{2}=\left\|x^{*}\right\|^{2}\right\}
$$

for every $x \in E$. By the Hahn-Banach theorem, $J(x)$ is nonempty; see [5] for more details. We denote the weak convergence and the strong convergence of a sequence $\left\{x_{n}\right\}$ to $x$ in $E$ by $x_{n} \rightarrow x$ and $x_{n} \rightarrow x$, respectively. We also denote the weak ${ }^{*}$ convergence of a sequence $\left\{x_{n}^{*}\right\}$ to $x^{*}$ in $E$ by $x_{n}^{*}-^{*} x^{*}$. A Banach space $E$ is said to be strictly convex if $\|x+y\| / 2<1$ for $x, y \in E$ with $\|x\|=\|y\|=1$ and $x \neq y$. It is also said to be uniformly convex if for each $\varepsilon \in(0,2]$, there exists $\delta>0$ such that $\|x+y\| / 2<1-\delta$ for $x, y \in E$ with $\|x\|=\|y\|=1$ and $\|x-y\| \geq \varepsilon$. A uniformly convex Banach space has the Kadec-Klee property, that is, $x_{n}-x$ and $\left\|x_{n}\right\| \rightarrow\|x\|$ imply $x_{n} \rightarrow x$. The space $E$ is said to be smooth if the limit

$$
\lim _{t \rightarrow 0} \frac{\|x+t y\|-\|x\|}{t}
$$


exists for all $x, y \in S(E)=\{z \in E:\|z\|=1\}$. It is also said to be uniformly smooth if the limit exists uniformly in $x, y \in S(E)$. We know that if $E$ is smooth, strictly convex, and reflexive, then the duality mapping $J$ is single valued, one to one, and onto; see [6] for more details.

Let $E$ be a smooth, strictly convex, and reflexive Banach space and let $C$ be a closed convex subset of $E$. Throughout this paper, we denote by $\phi$ the function defined by

$$
\phi(y, x)=\|y\|^{2}-2\langle y, J x\rangle+\|x\|^{2}, \quad \forall x, y \in E .
$$

Following Alber [7], the generalized projection $\Pi_{C}$ from $E$ onto $C$ is defined by $\Pi_{C}(x)=z$, where $z$ is the solution to the following minimization problem:

$$
\phi(z, x)=\min _{y \in C} \phi(y, x), \quad \forall x \in E .
$$

The generalized projection $\Pi_{C}$ from $E$ onto $C$ is well defined, single valued and satisfies

$$
(\|x\|-\|y\|)^{2} \leq \phi(y, x) \leq(\|x\|+\|y\|)^{2}, \quad \forall x, y \in E .
$$

If $E$ is a Hilbert space, then $\phi(y, x)=\|y-x\|^{2}$ and $\Pi_{C}$ is the metric projection of $E$ onto $C$. It is well know that the following conclusions for generalized projections hold.

Lemma 2.1 (Alber [7] and Kamimura and Takahashi [8]). Let $C$ be a nonempty closed convex subset of a smooth, strictly convex and reflexive Banach space Then

$$
\phi\left(x, \Pi_{C} y\right)+\phi\left(\Pi_{C} y, y\right) \leq \phi(x, y), \quad \forall x \in C, y \in E .
$$

Lemma 2.2. Let $C$ be a nonempty closed convex subset of a smooth, strictly convex and reflexive Banach space $E$, let $x \in E$, and let $z \in C$. Then

$$
z=\Pi_{C} x \Longleftrightarrow\langle y-z, J x-J z\rangle \leq 0, \quad \forall y \in C
$$

Let $C$ be a nonempty closed convex subset of a smooth, strictly convex and reflexive Banach space $E$, and let $T$ be a mapping from $C$ into itself. We denoted by $F(T)$ the set of fixed points of $T$. A point $p \in C$ is said to be an asymptotic fixed point of $T[9,10]$ if there exists $\left\{x_{n}\right\}$ in $C$ which converges weakly to $p$ and $\lim _{n \rightarrow \infty}\left\|x_{n}-T x_{n}\right\|=0$. We denote the set of all asymptotic fixed point of $T$ by $\widehat{F}(T)$. Following Matsushita and Takahashi [11], a mapping $T: C \rightarrow C$ is said to be relatively nonexpansive if the following conditions are satisfied:

(1) $F(T)$ is nonempty;

(2) $\phi(u, T x) \leq \phi(u, x)$, for all $u \in F(T), x \in C$;

(3) $\widehat{F}(T)=F(T)$.

The following lemma is due to Matsushita and Takahashi [11].

Lemma 2.3 (Matsushita and Takahashi [11]). Let $C$ be a nonempty closed convex subset of a smooth, strictly convex and reflexive Banach space $E$, and let $T$ be a relatively nonexpansive mapping from $C$ into itself. Then $F(T)$ is closed and convex. 
We also know the following lemmas.

Lemma 2.4 (see [8]). Let $E$ be a smooth and uniformly convex Banach space and let $\left\{x_{n}\right\}$ and $\left\{y_{n}\right\}$ be sequences in E such that either $\left\{x_{n}\right\}$ or $\left\{y_{n}\right\}$ is bounded. If $\lim _{n} \phi\left(x_{n}, y_{n}\right)=0$, then $\lim _{n}\left\|x_{n}-y_{n}\right\|=0$.

Lemma 2.5 (see [12]). Let $E$ be a uniformly convex Banach space and $B_{r}(0)$ be a closed ball of $E$. Then there exists a continuous, stricting increasing and convex function $g:[0, \infty) \rightarrow[0, \infty)$ with $g(0)=0$ such that

$$
\|\lambda x+\mu y+\gamma z\|^{2} \leq \lambda\|x\|^{2}+\mu\|y\|^{2}+\gamma\|z\|^{2}-\lambda \mu g(\|x-y\|)
$$

for all $x, y, z \in B_{r}(0)$ and $\lambda, \mu, \gamma \in[0,1]$.

For solving the equilibrium problem for bifunction $F: C \times C \rightarrow R$, let us assume that $F$ satisfies the following conditions:

$\left(A_{1}\right) F(x, x)=0$ for all $x \in C$;

$\left(A_{2}\right) F$ is monotone, that is, $F(x, y)+F(y, x) \leq 0$ for all $x, y \in C$;

$\left(A_{3}\right)$ for each $x, y, z \in C$,

$$
\limsup _{t \downarrow 0} F(t z+(1-t) x, y) \leq F(x, y)
$$

$\left(A_{4}\right)$ for each $x \in C, y \mapsto F(x, y)$ is a convex and lower semicontinuous.

If an equilibrium bifunction $F: C \times C \rightarrow R$ satisfies conditions $\left(A_{1}\right)-\left(A_{4}\right)$, then we have the following two important results.

Lemma 2.6 (see [13]). Let $C$ be a nonempty closed convex subset of a smooth, strictly convex and reflexive Banach space $E$, let $F$ be an equilibrium bifunction $F: C \times C \rightarrow R$ satisfying conditions $\left(A_{1}\right)-\left(A_{4}\right)$, and let $r>0$ for any given $x \in E$. Then, there exists $z \in C$ such that

$$
F(z, y)+\frac{1}{r}\langle y-z, J z-J x\rangle \geq 0, \quad \forall y \in C
$$

Lemma 2.7 (see [4]). Let $C$ be a nonempty closed convex subset of a uniformly smooth, strictly convex and reflexive Banach space $E$; let $F$ be an equilibrium bifunction $F: C \times C \rightarrow R$ satisfying conditions $\left(A_{1}\right)-\left(A_{4}\right)$. For $r>0$ and $x \in E$, define a mapping $T_{r}: E \rightarrow 2^{C}$ as follows:

$$
T_{r}(x)=\left\{z \in C: F(z, y)+\frac{1}{r}\langle y-z, J z-J x\rangle \geq 0, \forall y \in C\right\}
$$


for all $x \in E$. Then, the following holds:

(1) $T_{r}$ is single-valued;

(2) $T_{r}$ is a firmly nonexpansive-type mapping [27], that is, for any $x, y \in E$,

$$
\left\langle T_{r} x-T_{r} y, J T_{r} x-J T_{r} y\right\rangle \leq\left\langle T_{r} x-T_{r} y, J x-J y\right\rangle
$$

(3) $F\left(T_{r}\right)=\widehat{F}\left(T_{r}\right)=E P(F)$;

(4) $E P(F)$ is a closed and convex set.

Lemma 2.8 (see [4]). Let $C$ be a nonempty closed convex subset of a uniformly smooth, strictly convex and reflexive Banach space $E$; let $F$ be an equilibrium bifunction $F: C \times C \rightarrow R$ satisfying conditions $\left(A_{1}\right)-\left(A_{4}\right)$. For $r>0, x \in E$ and $q \in F\left(T_{r}\right)$,

$$
\phi\left(q, T_{r} x\right)+\phi\left(T_{r} x, x\right) \leq \phi(q, x)
$$

\section{The Main Results}

In this section, we prove a strong convergence theorem which is the main result in the paper.

Theorem 3.1. Let $E$ be a uniformly smooth and uniformly convex Banach space, and let $C$ be a nonempty closed convex subset of $E$. Let $A: C \rightarrow E^{*}$ be a continuous and monotone operator. Let $F$ be a bifunction from $C \times C$ to $R$ which satisfies $\left(A_{1}\right)-\left(A_{4}\right)$, let $S$ be a relatively nonexpansive mapping of $C$ into itself such that $F(S) \cap E P \cap F(f) \neq \emptyset$, and let $f: C \rightarrow C$ be a closed quasi- $\phi$-nonexpansive mapping. Let $\left\{x_{n}\right\}$ be the sequence generated by $x_{0}=x \in C, C_{0}=C$ and

$$
\begin{gathered}
y_{n}=J^{-1}\left(\alpha_{n} J f\left(x_{n}\right)+\beta_{n} J x_{n}+\gamma_{n} J S x_{n}\right), \\
u_{n} \in C \text { such that } F\left(u_{n}, y\right)+\left\langle A u_{n}, y-u_{n}\right\rangle+\frac{1}{r_{n}}\left\langle y-u_{n}, J u_{n}-J y_{n}\right\rangle \geq 0, \quad \forall y \in C, \\
C_{n+1}=\left\{z \in C_{n}: \phi\left(z, u_{n}\right) \leq \phi\left(z, x_{n}\right)\right\}, \\
x_{n+1}=\prod_{C_{n+1}} x
\end{gathered}
$$

for every $n \in N \cup\{0\}$, where $J$ is the duality mapping on $E,\left\{\alpha_{n}\right\},\left\{\beta_{n}\right\},\left\{\gamma_{n}\right\} \subset[0,1]$, and $\left\{r_{n}\right\} \subset$ $[a, \infty)$ for some $a>0$. If the following conditions are satisfied

$\left(C_{1}\right) \alpha_{n}+\beta_{n}+\gamma_{n}=1$,

$\left(C_{2}\right) \liminf _{n \rightarrow \infty} \beta_{n} \gamma_{n}>0 ; \liminf _{n \rightarrow \infty} \alpha_{n} \beta_{n}>0$,

then $\left\{x_{n}\right\}$ converges strongly to $\Pi_{F(S) \cap F(f) \cap E P} x$, where $\Pi_{F(S) \cap F(f) \cap E P}$ is the generalized projection of $E$ onto $F(S) \cap F(f) \cap E P$.

Proof. We define a bifunction $G: C \times C \rightarrow R$ by

$$
G(z, y)=F(z, y)+\langle A z, y-z\rangle, \quad \forall z, y \in C
$$


Next, we prove that the bifunction $G$ satisfies conditions $\left(A_{1}\right)-\left(A_{4}\right)$.

$\left(A_{1}\right) G(x, x)=0$ for all $x \in C$.

Since $G(x, x)=F(x, x)+\langle A x, 0\rangle=F(x, x)=0$, for all $x \in C$.

$\left(A_{2}\right) G$ is monotone, that is, $G(z, y)+G(y, z) \leq 0$ for all $y, z \in C$.

Since $A$ is a continuous and monotone operator, hence from the definition of $G$ we have

$$
\begin{aligned}
G(z, y)+G(y, z) & =F(z, y)+\langle A z, y-z\rangle+F(y, z)+\langle A y, z-y\rangle \\
& =F(z, y)+F(y, z)+\langle A z, y-z\rangle-\langle A y, y-z\rangle \\
& \leq 0+\langle A z-A y, y-z\rangle=-\langle A y-A z, y-z\rangle \leq 0 .
\end{aligned}
$$

$\left(A_{3}\right)$ For each $x, y, z \in C$,

$$
\limsup _{t \downarrow 0} G(t z+(1-t) x, y) \leq G(x, y)
$$

Since

$$
\begin{aligned}
\limsup _{t \downarrow 0} G(t z+(1-t) x, y)= & \underset{t \downarrow 0}{\limsup } F(t z+(1-t) x, y) \\
& +\limsup _{t \downarrow 0}\langle A(t z+(1-t) x), y-(t z+(1-t) x)\rangle \\
\leq & F(x, y)+\langle A x, y-x\rangle=G(x, y) .
\end{aligned}
$$

$\left(A_{4}\right)$ For each $x \in C, y \mapsto G(x, y)$ is a convex and lower semicontinuous.

For each $x \in C$, for all $t \in(0,1)$ and for all $y, z \in C$, since $F$ satisfies $\left(A_{4}\right)$, we have

$$
\begin{aligned}
G(x, t y+(1-t) z) & =F(x, t y+(1-t) z)+\langle A x, t y+(1-t) z-x\rangle \\
& \leq t[F(x, y)+\langle A x, y-x\rangle]+(1-t)[F(x, z)+\langle A x, z-x\rangle] \\
& =t G(x, y)+(1-t) G(x, z) .
\end{aligned}
$$

So, $y \mapsto G(x, y)$ is convex.

Similarly, we can prove that $y \mapsto G(x, y)$ is lower semicontinuous.

Therefore, the generalized equilibrium problem (1.1) is equivalent to the following equilibrium problem: find $z \in C$ such that

$$
G(z, y) \geq 0, \quad \forall y \in C
$$


and (3.1) can be written as

$$
\begin{gathered}
y_{n}=J^{-1}\left(\alpha_{n} J f\left(x_{n}\right)+\beta_{n} J x_{n}+\gamma_{n} J S x_{n}\right), \\
u_{n} \in C \text { such that } G\left(u_{n}, y\right)+\frac{1}{r_{n}}\left\langle y-u_{n}, J u_{n}-J y_{n}\right\rangle \geq 0, \quad \forall y \in C, \\
C_{n+1}=\left\{z \in C_{n}: \phi\left(z, u_{n}\right) \leq \phi\left(z, x_{n}\right)\right\}, \\
x_{n+1}=\prod_{C_{n+1}} x .
\end{gathered}
$$

Since the bifunction $G$ satisfies conditions $\left(A_{1}\right)-\left(A_{4}\right)$, from Lemma 2.7, for a given $r>$ 0 and $x \in C$, we can define a mapping $W_{r}: E \rightarrow 2^{C}$ as follows:

$$
W_{r}(x)=\left\{z \in C: G(z, y)+\frac{1}{r}\langle y-z, J z-J x\rangle \geq 0, \forall y \in C\right\}
$$

Moreover, $W_{r}$ satisfies the conclusions in Lemma 2.7.

Putting $u_{n}=W_{r_{n}} y_{n}$ for all $n \in N$, we have from Lemmas 2.7 and 2.8 that $W_{r_{n}}$ are relatively nonexpansive.

We divide the proof of Theorem 3.1 into six steps.

Step 1. We first show that $C_{n}$ is closed and convex. It is obvious that $C_{n}$ is closed. Since

$$
\phi\left(z, u_{n}\right) \leq \phi\left(z, x_{n}\right) \Longleftrightarrow\left\|u_{n}\right\|^{2}-\left\|x_{n}\right\|^{2}-2\left\langle z, J u_{n}-J x_{n}\right\rangle \geq 0,
$$

$C_{n}$ is convex. So, $C_{n}$ is a closed convex subset of $E$ for all $n \in N \cup\{0\}$.

Step 2. Next we show by induction that $\operatorname{EP}(G) \cap F(S) \cap F(f) \subset C_{n}$ for all $n \in N \cup\{0\}$. From $C_{0}=C$, we have

$$
\mathrm{EP}(G) \cap F(S) \cap F(f) \subset C_{0} .
$$


Suppose that $\mathrm{EP}(G) \cap F(S) \cap F(f) \subset C_{k}$ for some $k \in N \cup\{0\}$. For any $u \in \operatorname{EP}(G) \cap F(S) \cap F(f) \subset$ $C_{k}$, since $W_{r_{k}}$ and $S$ are relatively nonexpansive, $f$ is quasi- $\phi$-nonexpansive, we have

$$
\begin{aligned}
\phi\left(u, u_{k}\right)= & \phi\left(u, W_{r_{k}} y_{k}\right) \leq \phi\left(u, y_{k}\right)=\phi\left(u, J^{-1}\left(\alpha_{k} J f\left(x_{k}\right)+\beta_{k} J x_{k}+\gamma_{k} J S x_{k}\right)\right) \\
= & \|u\|^{2}-2\left\langle u, \alpha_{k} J f\left(x_{k}\right)+\beta_{k} J x_{k}+\gamma_{k} J S x_{k}\right\rangle+\left\|J^{-1}\left(\alpha_{k} J f\left(x_{k}\right)+\beta_{k} J x_{k}+\gamma_{k} J S x_{k}\right)\right\|^{2} \\
\leq & \|u\|^{2}-2 \alpha_{k}\left\langle u, J f\left(x_{k}\right)\right\rangle-2 \beta_{k}\left\langle u, J x_{k}\right\rangle-2 \gamma_{k}\left\langle u, J S x_{k}\right\rangle \\
& +\left\|\alpha_{k} J f\left(x_{k}\right)+\beta_{k} J x_{k}+\gamma_{k} J S x_{k}\right\|^{2} \\
\leq & \|u\|^{2}-2 \alpha_{k}\left\langle u, J f\left(x_{k}\right)\right\rangle-2 \beta_{k}\left\langle u, J x_{k}\right\rangle-2 \gamma_{k}\left\langle u, J S x_{k}\right\rangle \\
& +\alpha_{k}\left\|J f\left(x_{k}\right)\right\|^{2}+\beta_{k}\left\|J x_{k}\right\|^{2}+\gamma_{k}\left\|J S x_{k}\right\|^{2} \\
\leq & \alpha_{k}\left(\|u\|^{2}-2\left\langle u, J f\left(x_{k}\right)\right\rangle+\left\|f\left(x_{k}\right)\right\|^{2}\right)+\beta_{k}\left(\|u\|^{2}-2\left\langle u, J x_{k}\right\rangle+\left\|x_{k}\right\|^{2}\right) \\
& +\gamma_{k}\left(\|u\|^{2}-2\left\langle u, J S x_{k}\right\rangle+\left\|S x_{k}\right\|^{2}\right) \\
= & \alpha_{k} \phi\left(u, f\left(x_{k}\right)\right)+\beta_{k} \phi\left(u, x_{k}\right)+\gamma_{k} \phi\left(u, S x_{k}\right) \\
\leq & \alpha_{k} \phi\left(u, x_{k}\right)+\beta_{k} \phi\left(u, x_{k}\right)+\gamma_{k} \phi\left(u, x_{k}\right)=\phi\left(u, x_{k}\right) .
\end{aligned}
$$

Hence, we have $u \in C_{k+1}$. This implies that

$$
\mathrm{EP}(G) \cap F(S) \cap F(f) \subset C_{n}, \quad \forall n \in N \cup\{0\} .
$$

So, $\left\{x_{n}\right\}$ is well defined.

Step 3. Next we prove that the sequences $\left\{x_{n}\right\},\left\{S x_{n}\right\}$, and $\left\{f x_{n}\right\}$ are bounded. From the definition of $x_{n}$, we have

$$
\phi\left(x_{n}, x\right)=\phi\left(\Pi_{C_{n}} x, x\right) \leq \phi(u, x)-\phi\left(u, \Pi_{C_{n}} x\right) \leq \phi(u, x)
$$

for all $u \in \operatorname{EP}(G) \cap F(S) \cap F(f) \subset C_{n}$. Then $\phi\left(x_{n}, x\right)$ is bounded. Therefore, $\left\{x_{n}\right\},\left\{S x_{n}\right\}$, and $\left\{f x_{n}\right\}$ are bounded.

Step 4. Next we prove that

$$
\lim _{n \rightarrow \infty}\left\|x_{n+1}-x_{n}\right\|=0, \quad \lim _{n \rightarrow \infty}\left\|x_{n}-u_{n}\right\|=0, \quad \lim _{n \rightarrow \infty}\left\|x_{n}-S x_{n}\right\|=0, \quad \lim _{n \rightarrow \infty}\left\|x_{n}-f x_{n}\right\|=0 .
$$

From $x_{n+1} \in C_{n+1} \subset C_{n}$ and $x_{n}=\Pi_{C_{n}} x$, we have

$$
\phi\left(x_{n}, x\right) \leq \phi\left(x_{n+1}, x\right), \quad \forall n \in N \cup\{0\} .
$$


Journal of Inequalities and Applications

Thus, $\left\{\phi\left(x_{n}, x\right)\right\}$ is nondecreasing. So, the limit of $\left\{\phi\left(x_{n}, x\right)\right\}$ exists. Since

$$
\phi\left(x_{n+1}, x_{n}\right)=\phi\left(x_{n+1}, \Pi_{C_{n}} x\right) \leq \phi\left(x_{n+1}, x\right)-\phi\left(\Pi_{C_{n}} x, x\right)=\phi\left(x_{n+1}, x\right)-\phi\left(x_{n}, x\right)
$$

for all $n \in N \cup\{0\}$, we have $\lim _{n \rightarrow \infty} \phi\left(x_{n+1}, x_{n}\right)=0$. From $x_{n+1}=\Pi_{C_{n+1}} x \in C_{n+1}$, we have

$$
\phi\left(x_{n+1}, u_{n}\right) \leq \phi\left(x_{n+1}, x_{n}\right), \quad \forall n \in N \cup\{0\} .
$$

Therefore, we also have

$$
\lim _{n \rightarrow \infty} \phi\left(x_{n+1}, u_{n}\right)=0
$$

Since $\lim _{n \rightarrow \infty} \phi\left(x_{n+1}, x_{n}\right)=\lim _{n \rightarrow \infty} \phi\left(x_{n+1}, u_{n}\right)=0$ and $E$ is uniformly convex and smooth, we have from Lemma 2.4 that

$$
\lim _{n \rightarrow \infty}\left\|x_{n+1}-x_{n}\right\|=\lim _{n \rightarrow \infty}\left\|x_{n+1}-u_{n}\right\|=0 .
$$

So, we have

$$
\lim _{n \rightarrow \infty}\left\|x_{n}-u_{n}\right\|=0
$$

Since $J$ is uniformly norm-to-norm continuous on bounded sets and $\lim _{n \rightarrow \infty}\left\|x_{n}-u_{n}\right\|=0$, we have

$$
\lim _{n \rightarrow \infty}\left\|J x_{n}-J u_{n}\right\|=0
$$

For any $u \in \operatorname{EP}(G) \cap F(S) \cap F(f)$, from Lemma 2.5 and (3.8), we have

$$
\begin{aligned}
\phi\left(u, u_{n}\right)= & \phi\left(u, W_{r_{n}} y_{n}\right) \leq \phi\left(u, y_{n}\right)=\phi\left(u, J^{-1}\left(\alpha_{n} J f\left(x_{n}\right)+\beta_{n} J x_{n}+\gamma_{n} J S x_{n}\right)\right) \\
= & \|u\|^{2}-2\left\langle u, \alpha_{n} J f\left(x_{n}\right)+\beta_{n} J x_{n}+\gamma_{n} J S x_{n}\right\rangle+\left\|\alpha_{n} J f\left(x_{n}\right)+\beta_{n} J x_{n}+\gamma_{n} J S x_{n}\right\|^{2} \\
\leq & \left(\alpha_{n}+\beta_{n}+\gamma_{n}\right)\|u\|^{2}-2\left\langle u, \alpha_{n} J f\left(x_{n}\right)+\beta_{n} J x_{n}+\gamma_{n} J S x_{n}\right\rangle \\
& +\alpha_{n}\left\|J f\left(x_{n}\right)\right\|^{2}+\beta_{n}\left\|J x_{n}\right\|^{2}+\gamma_{n}\left\|J S x_{n}\right\|^{2}-\beta_{n} \gamma_{n} g\left(\left\|J x_{n}-J S x_{n}\right\|\right) \\
= & \alpha_{n}\left(\|u\|^{2}-2\left\langle u, J f\left(x_{n}\right)\right\rangle+\left\|f\left(x_{n}\right)\right\|^{2}\right)+\beta_{n}\left(\|u\|^{2}-2\left\langle u, J x_{n}\right\rangle+\left\|x_{n}\right\|^{2}\right) \\
& +\gamma_{n}\left(\|u\|^{2}-2\left\langle u, J S x_{n}\right\rangle+\left\|S x_{n}\right\|^{2}\right)-\beta_{n} \gamma_{n} g\left(\left\|J x_{n}-J S x_{n}\right\|\right) \\
= & \alpha_{n} \phi\left(u, f\left(x_{n}\right)\right)+\beta_{n} \phi\left(u, x_{n}\right)+\gamma_{n} \phi\left(u, S x_{n}\right)-\beta_{n} \gamma_{n} g\left(\left\|J x_{n}-J S x_{n}\right\|\right) \\
= & \phi\left(u, x_{n}\right)-\beta_{n} \gamma_{n} g\left(\left\|J x_{n}-J S x_{n}\right\|\right) .
\end{aligned}
$$


Therefore, we have

$$
\beta_{n} \gamma_{n} g\left(\left\|J x_{n}-J S x_{n}\right\|\right) \leq \phi\left(u, x_{n}\right)-\phi\left(u, u_{n}\right)
$$

Since

$$
\begin{aligned}
\phi\left(u, x_{n}\right)-\phi\left(u, u_{n}\right) & =\left\|x_{n}\right\|^{2}-\left\|u_{n}\right\|^{2}-2\left\langle u, J x_{n}-J u_{n}\right\rangle \\
& \leq\left|\left\|x_{n}\right\|^{2}-\left\|u_{n}\right\|^{2}\right|+2\left|\left\langle u, J x_{n}-J u_{n}\right\rangle\right| \\
& \leq\|\| x_{n}\|-\| u_{n}\left\|\mid\left(\left\|x_{n}\right\|+\left\|u_{n}\right\|\right)+2\right\| u\|\cdot\| J x_{n}-J u_{n} \| \\
& \leq\left\|x_{n}-u_{n}\right\|\left(\left\|x_{n}\right\|+\left\|u_{n}\right\|\right)+2\|u\| \cdot\left\|J x_{n}-J u_{n}\right\|,
\end{aligned}
$$

from (3.21) and (3.22), we have

$$
\lim _{n \rightarrow \infty}\left(\phi\left(u, x_{n}\right)-\phi\left(u, u_{n}\right)\right)=0 .
$$

Since $\lim \inf _{n \rightarrow \infty} \beta_{n} \gamma_{n}>0$, we have

$$
\lim _{n \rightarrow \infty} g\left(\left\|J x_{n}-J S x_{n}\right\|\right)=0
$$

Therefore, from the property of $g$, we have

$$
\lim _{n \rightarrow \infty}\left\|J x_{n}-J S x_{n}\right\|=0
$$

Since $J^{-1}$ is uniformly norm-to-norm continuous on bounded sets, we have

$$
\lim _{n \rightarrow \infty}\left\|x_{n}-S x_{n}\right\|=0
$$


Similarly, we have

$$
\begin{aligned}
\phi\left(u, u_{n}\right)= & \phi\left(u, W_{r_{n}} y_{n}\right) \leq \phi\left(u, y_{n}\right)=\phi\left(u, J^{-1}\left(\alpha_{n} J f\left(x_{n}\right)+\beta_{n} J x_{n}+\gamma_{n} J S x_{n}\right)\right) \\
= & \|u\|^{2}-2\left\langle u, \alpha_{n} J f\left(x_{n}\right)+\beta_{n} J x_{n}+\gamma_{n} J S x_{n}\right\rangle+\left\|\alpha_{n} J f\left(x_{n}\right)+\beta_{n} J x_{n}+\gamma_{n} J S x_{n}\right\|^{2} \\
\leq & \left(\alpha_{n}+\beta_{n}+\gamma_{n}\right)\|u\|^{2}-2\left\langle u, \alpha_{n} J f\left(x_{n}\right)+\beta_{n} J x_{n}+\gamma_{n} J S x_{n}\right\rangle \\
& +\alpha_{n}\left\|J f\left(x_{n}\right)\right\|^{2}+\beta_{n}\left\|J x_{n}\right\|^{2}+\gamma_{n}\left\|J S x_{n}\right\|^{2}-\alpha_{n} \beta_{n} g\left(\left\|J x_{n}-J f x_{n}\right\|\right) \\
= & \alpha_{n}\left(\|u\|^{2}-2\left\langle u, J f\left(x_{n}\right)\right\rangle+\left\|f\left(x_{n}\right)\right\|^{2}\right)+\beta_{n}\left(\|u\|^{2}-2\left\langle u, J x_{n}\right\rangle+\left\|x_{n}\right\|^{2}\right) \\
& +\gamma_{n}\left(\|u\|^{2}-2\left\langle u, J S x_{n}\right\rangle+\left\|S x_{n}\right\|^{2}\right)-\alpha_{n} \beta_{n} g\left(\left\|J x_{n}-J f x_{n}\right\|\right) \\
= & \alpha_{n} \phi\left(u, f\left(x_{n}\right)\right)+\beta_{n} \phi\left(u, x_{n}\right)+\gamma_{n} \phi\left(u, S x_{n}\right)-\alpha_{n} \beta_{n} g\left(\left\|J x_{n}-J f x_{n}\right\|\right) \\
= & \phi\left(u, x_{n}\right)-\alpha_{n} \beta_{n} g\left(\left\|J x_{n}-J f x_{n}\right\|\right) .
\end{aligned}
$$

Therefore, we have

$$
\alpha_{n} \beta_{n} g\left(\left\|J x_{n}-J f x_{n}\right\|\right) \leq \phi\left(u, x_{n}\right)-\phi\left(u, u_{n}\right) .
$$

From (3.26) and $\lim \inf _{n \rightarrow \infty} \alpha_{n} \beta_{n}>0$, we have

$$
\lim _{n \rightarrow \infty} g\left(\left\|J x_{n}-J f x_{n}\right\|\right)=0 .
$$

Therefore, from the property of $g$, we have

$$
\lim _{n \rightarrow \infty}\left\|J x_{n}-J f x_{n}\right\|=0
$$

Since $J^{-1}$ is uniformly norm-to-norm continuous on bounded sets, we have

$$
\lim _{n \rightarrow \infty}\left\|x_{n}-f x_{n}\right\|=0
$$

Step 5. Next we prove that

$$
W_{w}\left(x_{n}\right) \subset F(S) \cap \operatorname{EP}(G) \cap F(f),
$$

where $W_{w}\left(x_{n}\right)=\left\{p \in C\right.$, there exists subsequence $\left\{x_{n_{k}}\right\} \subset\left\{x_{n}\right\}$ such that $\left.x_{n_{k}} \rightarrow p\right\}$.

(a) We prove that $W_{w}\left(x_{n}\right) \subset F(S)$.

In fact, for any given $p \in W_{w}\left(x_{n}\right)$, there exists a subsequence $\left\{x_{n_{k}}\right\}$ of $\left\{x_{n}\right\}$ such that $x_{n_{k}} \rightarrow p$. Since $\left\|x_{n_{k}}-S x_{n_{k}}\right\| \rightarrow 0$ and $S$ is relatively nonexpansive, we have $p \in \widehat{F}(S)=F(S)$, that is, $W_{w}\left(x_{n}\right) \subset F(S)$. 
(b) We prove that $W_{w}\left(x_{n}\right) \subset \operatorname{EP}(G)$.

In fact, from $u_{n}=W_{r_{n}} y_{n},(3.12)$ and Lemma 2.8, we have that

$$
\begin{aligned}
\phi\left(u_{n}, y_{n}\right) & =\phi\left(W_{r_{n}} y_{n}, y_{n}\right) \leq \phi\left(u, y_{n}\right)-\phi\left(u, W_{r_{n}} y_{n}\right) \leq \phi\left(u, x_{n}\right)-\phi\left(u, W_{r_{n}} y_{n}\right) \\
& =\phi\left(u, x_{n}\right)-\phi\left(u, u_{n}\right) .
\end{aligned}
$$

Hence it follows from (3.26) that

$$
\lim _{n \rightarrow \infty} \phi\left(u_{n}, y_{n}\right)=0
$$

Since $E$ is uniformly convex and smooth and $\left\{u_{n}\right\}$ is bounded, we have from Lemma 2.4 that

$$
\lim _{n \rightarrow \infty}\left\|u_{n}-y_{n}\right\|=0
$$

For any given $p \in W_{w}\left(x_{n}\right)$, there exists a subsequence $\left\{x_{n_{k}}\right\} \subset\left\{x_{n}\right\}$ such that $x_{n_{k}} \rightarrow p$. Since $\left\|x_{n}-u_{n}\right\| \rightarrow 0$, we have $u_{n_{k}} \rightarrow p$.

Since $J$ is uniformly norm-to-norm continuous on bounded sets, from (3.38), we have

$$
\lim _{n \rightarrow \infty}\left\|J u_{n}-J y_{n}\right\|=0
$$

From $r_{n} \geq a$, we have

$$
\lim _{n \rightarrow \infty} \frac{\left\|J u_{n}-J y_{n}\right\|}{r_{n}}=0
$$

By $u_{n}=W_{r_{n}} y_{n}$, we have

$$
G\left(u_{n}, y\right)+\frac{1}{r_{n}}\left\langle y-u_{n}, J u_{n}-J y_{n}\right\rangle \geq 0, \quad \forall y \in C .
$$

Replacing $n$ by $n_{k}$, we have from $\left(A_{2}\right)$ that

$$
\frac{1}{r_{n_{k}}}\left\langle y-u_{n_{k}}, J u_{n_{k}}-J y_{n_{k}}\right\rangle \geq-G\left(u_{n_{k}}, y\right) \geq G\left(y, u_{n_{k}}\right), \quad \forall y \in C .
$$

Since $G(x, \cdot)$ is convex and lower semicontinuous, it is also weakly lower semicontinuous. So, letting $k \rightarrow \infty$, we have from (3.42) and $\left(A_{4}\right)$ that

$$
G(y, p) \leq 0, \quad \forall y \in C
$$

For any $t$ with $0<t \leq 1$ and $y \in C$, let $y_{t}=t y+(1-t) p$. Since $y \in C$ and hence $G\left(y_{t}, p\right) \leq 0$, from conditions $\left(A_{1}\right)$ and $\left(A_{4}\right)$, we have

$$
0=G\left(y_{t}, y_{t}\right) \leq t G\left(y_{t}, y\right)+(1-t) G\left(y_{t}, p\right) \leq t G\left(y_{t}, y\right)
$$


This implies that $G\left(y_{t}, y\right) \geq 0$. Hence from condition $\left(A_{3}\right)$, we have $G(p, y) \geq 0$ for all $y \in C$, and hence $p \in \operatorname{EP}(G)$.

(c) Now we prove that $W_{w}\left(x_{n}\right) \subset F(f)$.

In fact, for any given $p \in W_{w}\left(x_{n}\right)$, there exists a subsequence $\left\{x_{n_{j}}\right\}$ such that $x_{n_{j}} \rightarrow p$. Since $C_{j} \subset C_{n}$, for all $j \geq n$, we have $x_{j} \in C_{n}$, for all $j \geq n$. Since $C_{n}$ is a closed convex subset of $E$. we have $p \in C_{n}$ for all $n \geq 1$, that is, $p \in \bigcap_{n=1}^{\infty} C_{n}$. From (3.14) and (3.16), we have

$$
\phi\left(x_{n}, x\right) \leq \phi\left(x_{n+1}, x\right) \leq \phi(p, x) .
$$

Since the norm is weakly lower semicontinuous, we have

$$
\begin{aligned}
\phi(p, x) & =\|p\|^{2}-2\langle p, J x\rangle+\|x\|^{2} \leq \liminf _{n_{j} \rightarrow \infty}\left(\left\|x_{n_{j}}\right\|^{2}-2\left\langle x_{n_{j}}, J x\right\rangle+\|x\|^{2}\right) \\
& =\liminf _{n_{j} \rightarrow \infty} \phi\left(x_{n_{j}}, x\right) \leq \limsup _{n_{j} \rightarrow \infty} \phi\left(x_{n_{j}}, x\right) \leq \phi(p, x),
\end{aligned}
$$

that is, $\phi\left(x_{n_{i}}, x\right) \rightarrow \phi(p, x)$, then, $\left\|x_{n_{j}}\right\| \rightarrow\|p\|$. Since $E$ is uniformly convex Banach space, $E$ has a Kadec-Klee property, we have $x_{n_{j}} \rightarrow p$. From (3.34) and $f$ being closed, we have $f(p)=p$, that is, $p \in F(f)$.

Step 6. Finally we prove that

$$
x_{n} \longrightarrow w,
$$

where $w=\Pi_{F(S) \cap F(f) \cap E \mathrm{P}} x$. From $x_{n}=\Pi_{C_{n}} x$ and $w \in F(S) \cap \mathrm{EP}(G) \cap F(f) \subset C_{n}$, we have

$$
\begin{aligned}
\phi(p, x) & =\|p\|^{2}-2\langle p, J x\rangle+\|x\|^{2} \leq \liminf _{k \rightarrow \infty}\left(\left\|x_{k}\right\|^{2}-2\left\langle x_{k}, J x\right\rangle+\|x\|^{2}\right) \\
& =\liminf _{k \rightarrow \infty} \phi\left(x_{k}, x\right) \leq \limsup _{k \rightarrow \infty} \phi\left(x_{k}, x\right) \leq \phi(w, x) .
\end{aligned}
$$

From the definition of $\Pi_{F(S) \cap F(f) \cap E P}$, we have $p=w$. Hence, $\lim _{k \rightarrow \infty} \phi\left(x_{k}, x\right)=\phi(w, x)$. Therefore, we have

$$
\begin{aligned}
0 & =\lim _{k \rightarrow \infty}\left(\phi\left(x_{k}, x\right)-\phi(w, x)\right) \\
& =\lim _{k \rightarrow \infty}\left(\left\|x_{k}\right\|^{2}-\|w\|^{2}-2\left\langle x_{k}-w, J x\right\rangle\right) \\
& =\lim _{k \rightarrow \infty}\left(\left\|x_{k}\right\|^{2}-\|w\|^{2}\right) .
\end{aligned}
$$

Since $E$ has the Kadec-Klee property, we have that $x_{n} \rightarrow w=\prod_{F(S) \cap F(f) \cap E \mathrm{P}} x$. Therefore, $\left\{x_{n}\right\}$ converges strongly to $\Pi_{F(S) \cap F(f) \cap E P} x$.

This completes the proof of Theorem 3.1. 
Theorem 3.2. Let $E$ be a uniformly smooth and uniformly convex Banach space, and let $C$ be a nonempty closed convex subset of $E$. and $A: C \rightarrow E^{*}$ be a continuous and monotone operator. Let $F$ be a bifunction from $C \times C$ to $R$ which satisfies $\left(A_{1}\right)-\left(A_{4}\right)$ and let $S$ be a relatively nonexpansive mapping of $C$ into itself such that $F(S) \cap E P \neq \emptyset$. Let $\left\{x_{n}\right\}$ be the sequence generated by $x_{0}=x \in$ $C, C_{0}=C$, and

$$
\begin{gathered}
y_{n}=J^{-1}\left(\beta_{n} J x_{n}+\left(1-\beta_{n}\right) J S x_{n}\right), \\
u_{n} \in C \text { such that } F\left(u_{n}, y\right)+\left\langle A u_{n}, y-u_{n}\right\rangle+\frac{1}{r_{n}}\left\langle y-u_{n}, J u_{n}-J y_{n}\right\rangle \geq 0, \quad \forall y \in C, \\
C_{n+1}=\left\{z \in C_{n}: \phi\left(z, u_{n}\right) \leq \phi\left(z, x_{n}\right)\right\}, \\
x_{n+1}=\prod_{C_{n+1}} x
\end{gathered}
$$

for every $n \in N \cup\{0\}$, where $J$ is the duality mapping on $E,\left\{\beta_{n}\right\} \subset[0,1]$ satisfies $\lim \inf _{n \rightarrow \infty} \beta_{n}(1-$ $\left.\beta_{n}\right)>0$ and $\left\{r_{n}\right\} \subset[a, \infty)$ for some $a>0$. Then $\left\{x_{n}\right\}$ converges strongly to $\Pi_{F(S) \cap E P} x$, where $\Pi_{F(S) \cap E P}$ is the generalized projection of $E$ onto $F(S) \cap E P$.

Proof. In Theorem 3.1, take $f=S$, we get $\alpha_{n}+\gamma_{n}=1-\beta_{n}$. Therefore, the conclusion of Theorem 3.2 can be obtained from Theorem 3.1.

Remark 3.3. Theorem 3.1 in [3] and Theorem 3.1 in [4] are special cases of Theorem 3.2.

\section{Acknowledgment}

The authors would like to express their thanks to the referees for their helpful suggestions and comments.

\section{References}

[1] A. Tada and W. Takahashi, "Weak and strong convergence theorems for a nonexpansive mapping and an equilibrium problem," Journal of Optimization Theory and Applications, vol. 133, no. 3, pp. 359-370, 2007.

[2] S. Takahashi and W. Takahashi, "Viscosity approximation methods for equilibrium problems and fixed point problems in Hilbert spaces," Journal of Mathematical Analysis and Applications, vol. 331, no. 1, pp. 506-515, 2007.

[3] S. Takahashi and W. Takahashi, "Strong convergence theorem for a generalized equilibrium problem and a nonexpansive mapping in a Hilbert space," Nonlinear Analysis: Theory, Methods \& Applications, vol. 69, no. 3, pp. 1025-1033, 2008.

[4] W. Takahashi and K. Zembayashi, "Strong convergence theorem by a new hybrid method for equilibrium problems and relatively nonexpansive mappings," Fixed Point Theory and Applications, vol. 2008, Article ID 528476, 11 pages, 2008.

[5] W. Takahashi, Nonlinear Functional Analysis, Fixed Point Theory and Its Applications, Yokohama Publishers, Yokohama, Japan, 2000.

[6] I. Cioranescu, Geometry of Banach Spaces, Duality Mappings and Nonlinear Problems, vol. 62 of Mathematics and Its Applications, Kluwer Academic Publishers, Dordrecht, The Netherlands, 1990.

[7] Y. I. Alber, "Metric and generalized projection operators in Banach spaces: properties and applications," in Theory and Applications of Nonlinear Operators of Accretive and Monotone Type, A. G. Kartsatos, Ed., vol. 178 of Lecture Notes in Pure and Applied Mathematics, pp. 15-50, Dekker, New York, NY, USA, 1996. 
[8] S. Kamimura and W. Takahashi, "Strong convergence of a proximal-type algorithm in a Banach space," SIAM Journal on Optimization, vol. 13, no. 3, pp. 938-945, 2002.

[9] Y. Censor and S. Reich, "Iterations of paracontractions and firmly nonexpansive operators with applications to feasibility and optimization," Optimization, vol. 37, no. 4, pp. 323-339, 1996.

[10] S. Reich, "A weak convergence theorem for the alternating method with Bregman distances," in Theory and Applications of Nonlinear Operators of Accretive and Monotone Type, A. G. Kartsatos, Ed., vol. 178 of Lecture Notes in Pure and Applied Mathematics, pp. 313-318, Dekker, New York, NY, USA, 1996.

[11] S.-Y. Matsushita and W. Takahashi, "Weak and strong convergence theorems for relatively nonexpansive mappings in Banach spaces," Fixed Point Theory and Applications, vol. 2004, no. 1, pp. 37-47, 2004

[12] Y. J. Cho, H. Zhou, and G. Guo, "Weak and strong convergence theorems for three-step iterations with errors for asymptotically nonexpansive mappings," Computers \& Mathematics with Applications, vol. 47, no. 4-5, pp. 707-717, 2004.

[13] E. Blum and W. Oettli, "From optimization and variational inequalities to equilibrium problems," The Mathematics Student, vol. 63, no. 1-4, pp. 123-145, 1994. 